\title{
Study on Index System of Smart Community Construction
}

\author{
Guihua Liu*, Pu Zhang, Yu Feng \\ School of Public Affairs and Law, Southwest Jiaotong University, Chengdu, China \\ "Corresponding author.Email: ktflower@126.com
}

\begin{abstract}
The construction of an index system is closely related to the overall standards and evaluation issues in the construction of a smart community, and can even affect the effectiveness of the future construction. The construction of smart community in China is still in its infancy, and its index system needs to be improved. Based on the research and analysis of several existing official index systems in China, and considering the development situation of current urban communities around the world, we designed the overall framework of smart community index system in this paper. The framework highlights the structural relationships among the six layers, including the user layer, application layer, platform layer, infrastructure layer, guarantee layer and evaluation layer. On this basis, we further established a smart community index system under three levels of indexes, and briefly explains the system. Compared with previous studies, it highlights the importance of energy conservation, emission reduction, green and sustainable development, residents' participation, and technological integration in the construction of smart communities in the future.
\end{abstract}

Keywords: Smart community, index system, standard, construction

\section{INTRODUCTION}

The community is a micro component of a city, and the development of a city cannot be separated from the development of the community. The research on the smart community is a frontier area in the modern community development. As early as the 1990 s, when the International Communication Center of the University of San Diego in the United States faced the circumstance that the traditional practice cannot overcome current socio-economic challenges posed by the rapid development of information technology, the slogan of "Smart Communities" was first formally proposed [1]. Later it gradually developed better and better in the United States, Britain, Japan and other countries. With the advent of a new round of information revolution, the intelligent, network, and information construction of communities has become a boom in the development of urban communities. Although experts and scholars have not yet concluded a unified definition of an smart community, it is obviously that the smart community distinguishes from other ordinary communities as it fully integrates the new concept of community construction, and comprehensively applies the new generation of information technology such as the Internet of Things, big data, cloud computing, and even Artificial Intelligence, and moreover, it can bring much convenience to the residents in their study, work and daily life from multi-dimension and multi-level[2].

So what exactly does a smart community include? How to build a smart community scientifically? This requires a reasonable index system to guide. The construction of the index system is related to the overall standards and evaluation of the construction of smart communities, and can even affect the effectiveness of the later construction of smart communities. The construction of smart communities in China is still in the initial stage, and its index system is still immature. In recent years, the state has explicitly proposed the upper-level design for the new-type urbanization and the strengthening of community governance in the report of the "19th National Congress" and the "13th Five-Year Plan". The development of the smart communities is the fundamental work for building a smart city, and also an integral component of new-typed urbanization. In addition, its standard system has attracted the attention of governments at all levels, relevant enterprises and academia. Therefore, it is necessary to conduct deeply research on the index system of smart communities.

\section{EXISTING DOMESTIC SMART COMMUNITY INDEX SYSTEMS}

\subsection{Beijing Smart Community Construction Index System}

The Beijing Municipal Office of Social Affairs, the Municipal Economic Information Commission, and the Civil Affairs Bureau jointly issued a document of Guiding Standards for the Construction of Beijing's Smart 
Communities in December 2013. It clearly stated that the standard structure of smart communities includes 6 first-level indexes, 22 Secondary indexes, and 38 tertiary indexes (specific indexes). Specifically, the first-level indexes include three basic standards, one encouragement innovation standard, one guarantee standard, and one evaluation standard.

The guidelines in Beijing have been clearly classified into basic standards, innovation standards, guarantee standards, and evaluation standards, which has significance in the perspectives of encouraging innovation and perfecting assessment criteria. However, they did not construct an overall framework for each subject at different levels thus each part appeared to be scattered and loosely connected. What's more, it lacked the evaluation index for information and data platforms, which should have been an important part of the system.

\subsection{Shenzhen Smart Community Construction Index System}

The document of Shenzhen Smart Community Construction Guidelines (Trial) issued by Shenzhen Housing and Urban-Rural Construction Bureau in September 2014 also explained the overall framework and evaluation system of smart community construction. The index system has 5 first-level indexes, namely security system, construction and municipal facilities, information infrastructure, platforms, and smart applications; it covers 14 second-level indexes, and 58 third-level indexes which have been classified into the mandatory, the superior and the optional.

Shenzhen's index system is very specific and comprehensive in terms of infrastructure evaluation. However, it still needs further improvement and perfection in the design of the application layer (that is, smart applications), particularly in the community management and service.

\subsection{Smart Community Index System of the Ministry of Housing and Urban-Rural Development}

The Smart Community Construction Guide (Trial) issued by the Ministry of Housing and Urban-Rural Development in May 2014 also designed the evaluation index system for smart communities. Its evaluation index system involves six areas, including security system, infrastructure and built environment, community governance and public services, community management services, convenience services and theme communities. The indexes system contains with 6 first-level indexes, 23 second-level indexes, and 87 three-level indexes which have been classified into 26 control items, 43 general items, and 18 preferred items and also provided an index description and specific quantifiable evaluation criteria for each three-level index.

The evaluation index system of the Ministry of Housing and Urban-Rural Development is based on the basic situation that China's smart community construction is still in the initial stage, and it is more comprehensive and detailed than other local index systems. However, there are still some problems: (1) the unreasonable or even false classification and the overlapping contents of the index; (2) It is questionable whether to cover a certain index or not considering the fact that the construction of China's smart community is still in the initial stage, e.g. the indexes of the theme community; (3) Whether does this old-versioned index system made in 2014 meet the requirements of developing smart communities in the new era? Only by further improving the index design of smart communities can the above problems be solved.

\section{INDEX SYSTEM FOR SMART COMMUNITY CONSTRUCTION}

\subsection{Overall Framework of Index System}

Aiming at the shortcomings of the smart community index systems given by some domestic cities and the Ministry of Housing and Urban-Rural Development, we attempts to rebuild a more scientific and reasonable index system in this paper. In the overall framework of the research, the index system includes six layers: user layer, application layer, platform layer, infrastructure layer, guarantee layer, and evaluation layer (see Figure 1 for the overall framework). The six layers are divided into three parts. Among them, the user layer is the first part of the entire index system. This layer runs through the entire index system. The users involved in the user layer mainly include residents, governments, enterprises, and other organizations. The application layer, platform layer, and infrastructure layer are the second main part of the smart community index system. Some scholars refer to the platform layer and the information infrastructure (network layer, perception layer, and data layer) in the infrastructure as the technical system [3]. The infrastructure is divided into information infrastructure and municipal infrastructure. Finally, the basic part of the index system is the guarantee and evaluation layers. Among them, the guarantee layer is the basic condition to ensure the establishment and operation of the entire index system, and the evaluation layer is to improve the index system for the construction and operation of smart communities, which is conducive to the construction of smart communities in the future. 


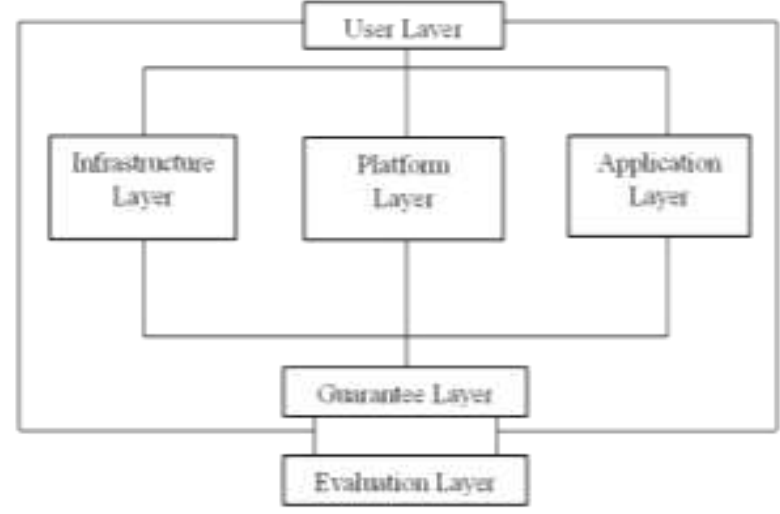

Figure 1 Framework of index system

\subsection{Content Description of Index System}

According to the above-designed framework figure, this study builds a brand-new and complete index system based on the reality of China's smart community construction. The main content of the index system is explained as follows. The entire smart community index system includes 6 first-level indexes, they are: the guarantee layer, information infrastructure layer, municipal infrastructure layer, platform layer, application layer, and evaluation layer. There are also 20 second-level indexes and 84 third-level indexes (including 70 specific construction indexes and 14 evaluation layer indexes).

\subsubsection{Guarantee layer}

The guarantee layer includes four second-level indexes of policies and regulations, design guarantee, operation guarantee and other guarantees. Among them, policies and regulations involve two third-level indexes of government policies, laws and regulations. Government policy refers to the official policies or system standards that guarantee the construction and operation of smart communities; laws and regulations refer to the relevant laws and regulations in the construction of smart communities. Design guarantee involves two third-level indexes of overall planning (design) and implementation plans. Operational guarantee involves four third-level indexes: capital guarantee, talent guarantee, management guarantee, and safety guarantee. Other guarantees involve evaluation and assessment, and residents' participation in two third-level indexes. The guarantee layer is the basic condition that enables the entire index system to be established and operated.

\subsubsection{Information infrastructure layer}

It includes three second-level indexes of network facilities, sensing facilities, and data facilities. As for the third-level indexes, the network facilities include wired broadband networks, wireless networks, mobile communication networks, and radio and television networks. Sensing facilities include smart cards, security sensors, radio frequency identification, detectors, and intelligent video surveillance. Data facilities include data collection, data integration, data storage, data exchange and sharing, basic databases, professional databases, and data security indexes.

\subsubsection{Municipal infrastructure layer}

It includes three second-level indexes of smart municipal facilities, smart service facilities, green facilities and the environment. Smart municipal facilities include the following third-level indexes: intelligent power supply network, intelligent gas supply network, intelligent water supply and drainage network, and intelligent transportation network. Smart service facilities include the following third-level indexes: medical and health facilities, cultural and sports facilities, elderly care facilities, emergency sites, and community comprehensive service centers. Green facilities and environment include the following third-level indexes: acoustic environment, water environment, air quality, community green space, comprehensive use of renewable energy, comprehensive use of water resources, and green buildings for energy saving and emission reduction. Among them, the acoustic environment, water environment, air quality, and green space of smart communities must meet relevant national standards.

\subsubsection{Platform layer}

It includes two second-level indexes of intelligent information platform and intelligent service platform. The intelligent information platform includes three third-level indexes: information cloud computing platform, information analysis platform for big data, and security and management platform for comprehensive information. The intelligent service platform includes two third-level indexes of public service platform and commercial service platform. The public service platform can integrate the different information resources from various departments, including education, culture, pension, medical care, employment, law and other public services, and provide real convenience for residents' lives. The business service platform means that the community can provide a highly informatized platform for community enterprises and businesses by integrating community market information resources and creating a better market environment.

\subsubsection{Application layer}

It includes five second-level indexes of public services, community management, smart home, living services, and green services. Specifically, in terms of third-level indexes, public services include smart cultural and educational 
services, smart elderly care services, smart medical services, smart employment services, smart legal services, and smart comprehensive government services. Community management includes indexes such as residents' autonomous management, community property management, emergency disaster management, community security management, community environmental management, and community grid management. Smart home includes three indexes: smart home appliances, smart furniture, and smart security. Living services include smart property services, smart courier services, smart shopping services, smart housekeeping services, and smart parking services. Green services include three indexes: intelligent waste classification, intelligent environmental monitoring, and green travel services.

\subsubsection{Evaluation layer}

The evaluation layer includes three second-level indexes of evaluation contents, evaluation subjects, and evaluation standards. Among them, the evaluation contents refer to several dimensions considered in the evaluation, which are composed of five dimensions: overall satisfaction, convenience, safety and security, scientific rationality, greenness and sustainability, and can also be called the evaluation principle. The subjects of evaluation include residents, experts, social organizations and other organizations. Evaluation standards refer to the standard results of the comprehensive evaluation of the construction and operation of smart communities based on the above evaluation principles and contents. According to the standards, the results can be divided from one-star smart community to five-star smart community.

\section{SUMMARY}

This study is based on the actual construction situation of smart communities in China, and faces the development of international smart communities. To meet the development requirements of smart communities in the new era, we strive to provide a reasonable and scalable index system for the construction of smart communities. The overall framework of the smart community index system has been designed in this study, highlighting the six-level structural relationship of the user layer, application layer, platform layer, infrastructure layer, guarantee layer and evaluation layer involved in the index system. And we further established a smart community index system, including 6 first-level indexes, 20 second-level indexes and 84 third-level indexes (including 70 specific construction indexes and 14 evaluation layer indexes) in all. Compared with previous studies, it highlights the importance of energy conservation, emission reduction, green and sustainable development, residents' participation, and technology integration in the future construction of smart communities, and also highlights the practicality. At the same time, an evaluation layer has been innovatively added to the index system. The evaluation layer allows the users of the smart community to conduct a comprehensive evaluation of the construction of the smart community, and through the evaluation, it is helpful to improve the construction of smart community. The construction of a smart community is constantly advancing with the times, and its standard system should also be advancing with the times. Although we strive to build a more comprehensive index system in this study, yet there will be inadequacies in the research due to the limited level of knowledge. Hopefully, this study will be used as a reference and guidance for the research and construction of smart communities in the future.

\section{ACKNOWLEDGMENT}

This research was financially supported by the Chengdu Philosophy and Social Science Planning Project: Research on the construction of Chengdu smart community in the new era, June 2019-June 2020.

\section{REFERENCES}

[1] Shen Yue, Chai Yanwei, Ma Xiujun, Concept, model and framework of human-oriented smart community, J. Modern Urban Research. 10(2014) 13-17.

[2] Zhang Dapeng, Wang Yi, Research on the evaluation index system for the construction of smart community (park) area, J. Engineering Construction Standardization. 02 (2015) 71-76.

[3] Wan Biyu, Research on Standards of Smart Community in China, first ed., Beijing, 2018. 